\title{
The Language and Identity of Agueda in Nick Joaquin's May Day Eve: An Analysis of Linguistic Features and Stances
}

\author{
${ }^{1}$ Kay Tepait Juanillo, ${ }^{2}$ Seregena Ruth Labastida-Martinez \\ ${ }^{1,2}$ Department of Liberal Arts and Behavioral Sciences, Visayas State University \\ (kayjuanillo@gmail.com)
}

Article History: Submitted April 23 ${ }^{\text {rd }}$, 2020; Accepted June 30 ${ }^{\text {th }}, 2020$; Published July $6^{\text {th }}, 2020$

\begin{abstract}
Language is an important device in the construction of an individual's identity. However, Language not only identifies any particular individual but also sets its position inside the society. As a form of social behavior, language like other social behaviors, also distinguishes gender differences. This study investigates the linguistic features and the personal identity of Agueda in Nick Joaquin's May Day Eve. This study can be used to apprehend how women were influenced by the society and the culture of the Philippines during the 1800s. The researchers use Lakoff's Theory of Linguistic Features, and the Indexicality Principle by Bucholtz and Hall (2005) to analyze the language and identity of Agueda. Qualitative Content Analysis and descriptive research design are used to analyze thoroughly the utterances of Agueda which consist of linguistic features and stances. Based on the linguistic features and the stances analyzed, Agueda uses emphatic stress more to show assertiveness through her utterances, she also uses disalignment more, and she likes to position herself along the affective scale. The result of the study shows that Agueda is an assertive and strong willed young woman, who likes to do whatever she wants. Her utterances also show how resentful she has become after her marriage with Badoy. The conclusion can be drawn that language is an important factor in creating an identity of a person, and this identity can be formed through the stances and linguistic features, which are greatly affected by the society, culture, and people that surround an individual.
\end{abstract}

Keywords: identity construction, women's linguistic features, Nick Joaquin, stances, May Dayeve

\section{INTRODUCTION}

Members of society communicate, interact and socialize with the help of language. According to Bamberg, M., De Fina, A. \& Schriffin, D. (2011) if an interaction is ubiquitous and central to the enactment and negotiation of identity, so is language. Although it is true that people can convey their identities through many symbols, such as clothing, demeanour, or the use of certain objects, the single most important system of symbols for expressing and negotiating identities is language.

Moreover, Wardhaugh (1987) inferred that language also varies according to sex and occupation. The language of men differs subtly from that of women. From recent studies, some sociolinguists have found other features which reflect the differences between women and men. They found that men and women have different ways of speaking. Men and women have different language features although they speak the same language. Women and men are significantly not the same in using language. Pan (2011) also averred that as a form of social behavior, a language like other social behavior, entertains gender difference as well. 
He emphasized that gender differences are a fundamental fact of human life, and it is not surprising to find them reflected in language. How men and women communicate is explainable and predictable by determining the contextually relevant social dimension of gender.

According to Robin Lakoff (1973), a Woman's Language has created the attitude that women are marginal to the serious concerns of life, which are pre-empted by men. The marginality and powerlessness of women are reflected in both the ways women are expected to speak; and how women are spoken of. Speech about women implies an object, whose sexual nature requires euphemism, and whose social roles are derivative and dependent in relation to men. The personal identity of women thus is linguistically submerged; the language works against the treatment of women, as serious persons with individual views.

Different sociolinguistic studies carried on investigating the difference between men's and women's language, most sociolinguists have agreed that women used more standard forms than men who tend to use vernaculars. According to Holmes (2008 cited in Ahmad 2014), there are different reasons why women use more standard forms. First, the social norms of society that expect women's behavior as a model or guardian of society's values affect the language they use. In addition, women are more status-cautious than men. Women are alleged by a stereotypical expectation when they speak, whatever they say can be used against them as evidence of their deficiencies. Additionally, according to Holmes (2008), women feel inferior in society, so they try to acquire their social status by using standard speech forms. By using standard forms, women fulfill their own face-protection needs and those they talk to.

Moreover, it is impossible to remove language from the society, as language can only be understood in its social context. There has been general agreement among linguists that no two people speak the same, whether males or females, it is easy to know the educational level, social identity, and gender of someone from his/her language. Researchers of an individual's language use have shown that the only way that self-conceptions enter the social world is via some form of discourse, hence the analysis of women's linguistic features and stances.

This study is an analysis of the women's linguistic features and the construction of identity through the use of stances. This will be useful in understanding the character of Agueda in Nick Joaquin's May Day Eve, which is one of the most classic stories in Philippine literature in English and has become an important reading material for Filipino students.

Generally, this study also aims to analyze the women's linguistic features and stances in the construction of the personal identity of the Agueda in Nick Joaquin's May Day Eve. Specifically, it aims to (1) analyze the women's linguistic features found in the Agueda's utterances, (2) analyze the stances used by Agueda in her talk in-interaction, and (3) to create a composite identity of Agueda base on the linguistic features and stances analyzed.

\section{METHOD}

In conducting this research, the researchers used the Qualitative Content Analysis design. Qualitative Content Analysis was used since it subjectively analyzed the content of text data through the systematic classification process of coding and identifying themes or patterns. It goes beyond merely counting words or extracting objective content from texts to examine 
meanings, themes, and patterns that may be manifest or latent in a particular text. It allows researchers to understand social reality in a subjective but scientific manner (Zhang and Wildemuth, 2008). Additionally, qualitative content analysis is the most appropriate research design to be applied in this study since it aims to analyze thoroughly and interpret text data to draw inference towards the utterances of the short story. Moreover, the researchers applied Descriptive Research Design in analyzing the data. Using a descriptive approach was particularly appropriate because an accurate and authentic description was required.

The data of this research was taken from a literary work which is a short story. This short story is May Day Eve by the Filipino National Artist Nick Joaquin. It was written after World War II, and is one of Joaquin's signature stories, which became a classic in Philippine Literature in English. Together with Joaquin's other stories like The Mass of St. Sylvester, Doña Jeronima and Candido's Apocalypse, May Day Eve utilized the theme of magic realism long before the genre was made a trend in Latin American novels. The short story was published in 1947, it is a story originally intended for adult readers, but has later become required and important reading material for Filipino students.

The data source that the researchers used is the short story May Day Eve by Nick Joaquin and the words that show the women's linguistic features and stances of Agueda, the woman main character in the story. As the only instrument for this research, the researchers need to consider the pertinent features of the research to avoid biases. Moreover, this research regarded the role of the researchers as the outside viewer, also called as etic - wherein the researchers did not participate on any certain activity, phenomenon, or program related to the data.

\section{RESULTS AND DISCUSSION}

Based on the data analysis, the researchers identified women's linguistic features and the linguistic device, stance, which construct Agueda's identity. Women's linguistic features is divided into ten types, Lexical Hedges or Fillers, Tag Question, Rising Intonation on Declaratives, Empty Adjectives, Precise Color Term, Intensifier, Hypercorrect Grammar, Super Polite Form, Avoidance of Strong Swear Words, and Emphatic Stress. On the other hand, the linguistic device, Stance, can be divided into three types, namely Evaluation, Positioning, (Affective and Epistemic), and Alignment.

\section{Women's Linguistic Features}

Agueda's Linguistic Features is the first data analyzed in this study. The researchers analyzed Agueda's utterances and collected the Women's Linguistic Features found in these utterances. In this part, the researchers will present the analyzed and the collected data based on Lakoff's Theory of Women's Linguistic Features.

Robin Lakoff (1975) averred that women's language is widely influential in the study of language-use features. She claimed that women have a special register, the so-called female register. Some linguistic features were considered to be used exclusively or predominantly by women. Women's language shows up in all levels of grammar of English. The differences can be found in the choice and frequency of lexical items; in situations in which certain syntactic roles are performed; in intonation, and other super segmental patterns. 
There are ten types of Women's Linguistic Features according to Lakoff (1975) namely, lexical hedges or fillers, tag question, rising intonation on declarative, empty adjectives, precise color term, intensifier, hypercorrect grammar, super polite form, avoidance of strong swear words, and emphatic stress. However, not all of these linguistic features can be found in women's language, since the language used is also affected by norms of the society and the culture of a woman.

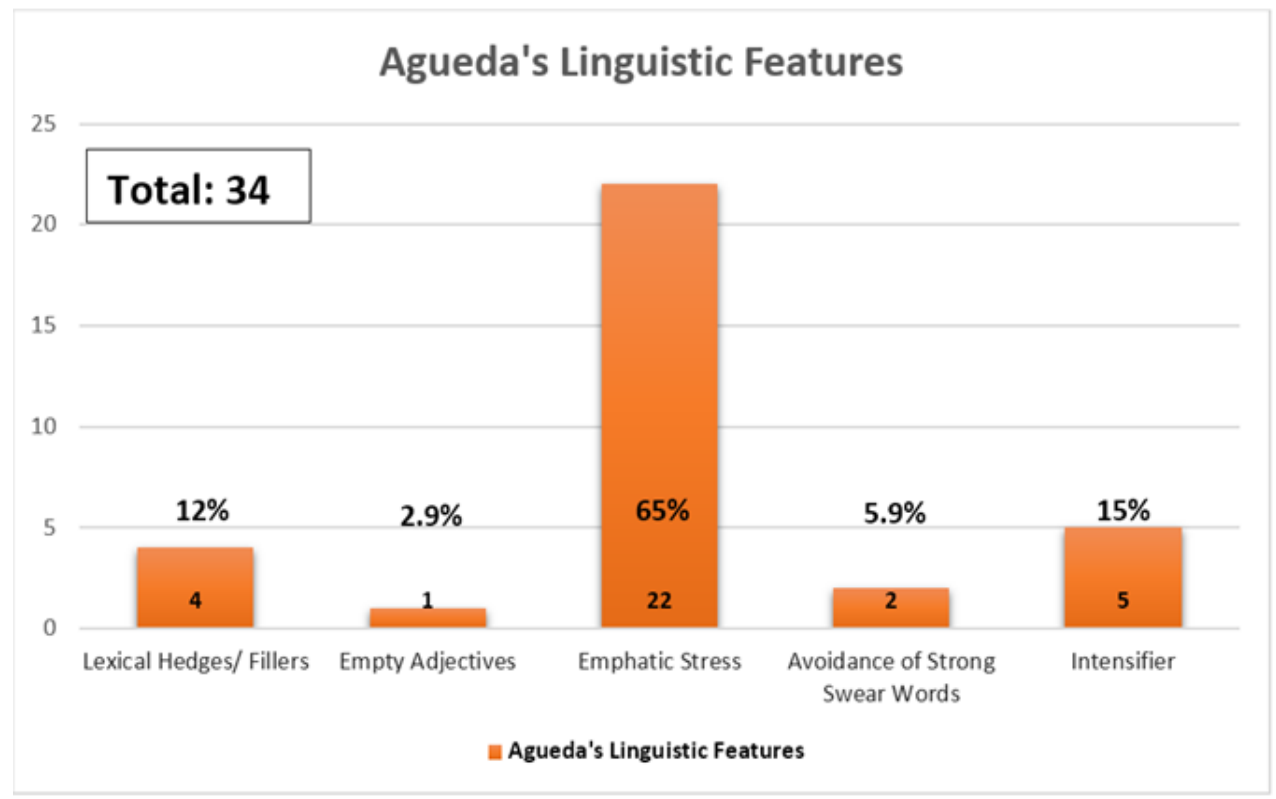

Figure 1 Frequency and Percentage of Agueda's Linguistic Features

As shown in figure 1 there are only five (5) women's linguistics features found in Agueda's utterances. These are Lexical Hedges/Fillers, Empty Adjectives, Emphatic Stress, Avoidance of Strong Swear Words, and Intensifier. Among all the linguistic features found, Emphatic Stress has the highest frequency (22 times or $65 \%$ ), followed by Intensifier (5 times or 15\%), Lexical Hedges/Fillers (4 times or 12\%), Avoidance of Strong Swear Words ( 2 times or $5.9 \%$ ), and Empty Adjectives with the frequency of one (1) or $2.9 \%$.

Below are some examples and discussion of the women's linguistic features found in Agueda's utterances:

\section{Lexical Hedges or Fillers}

The Lexical hedges according to Lakoff (2004) are part of women's speech that commonly contains words such as well, you know, sort of, like, perhaps, I think, I guess, etc., on the other hand, fillers or pause fillers are linguistic forms such as uh, um, and ah. The filler itself is a phrase which can appear anywhere in a sentence and can be deleted from the sentence with no change in context. The one purpose of lexical hedges is to show doubt or less confidence in the discourse.

In this study, the researchers were able to identify 4 (four) utterances of Agueda that contains Lexical hedges or Fillers. Below is an example of Agueda's utterance that contains Lexical hedges. 


\section{Excerpt 1:}

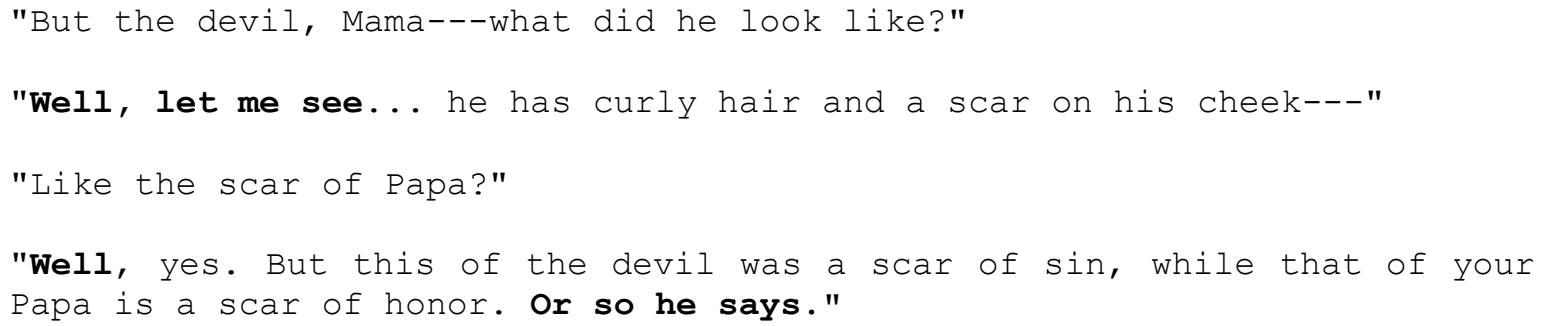

The excerpt above shows the conversation of Agueda and her daughter when they were talking about the devil Agueda saw when looking at the mirror one night. In their talk ininteraction, Agueda kept on using the word well, while describing or remembering the things that happened before. The discourse between Agueda and her daughter clearly shows her lack of confidence to tell her daughter that the devil she saw that night was the face of her husband, Badoy. She is having difficulties in starting her utterance, and she used the word well as a linguistic device to make the conversation smooth; and to solve the trouble of having to talk about the devil she saw in the mirror one May day eve.

The word well in the Agueda's discourse indicates her doubt or reservations in the things that she is telling her daughter. Agueda also started her utterances using the word well, which indicates her trouble in starting her utterance. Consequently, the sentence becomes indefinite because of the hedges that Agueda used.

\section{Empty Adjectives}

Empty adjectives are adjectives that only convey an emotional reaction rather than specific information. Adjectives are applied to soften and add friendly elements to the sentence, although they are not adding any particular meaning to content. Empty adjectives become one of the characteristics of women's speech since they reflect how women are uninvolved and out of power in uttering a sentence. Also, these linguistic feature indicates a speaker's approbation or admiration towards a certain subject (Khoirot, 2016). The researchers were able to identify only one (1) utterance of Agueda that shows an empty adjective as the linguistic feature.

\section{Excerpt 2:}

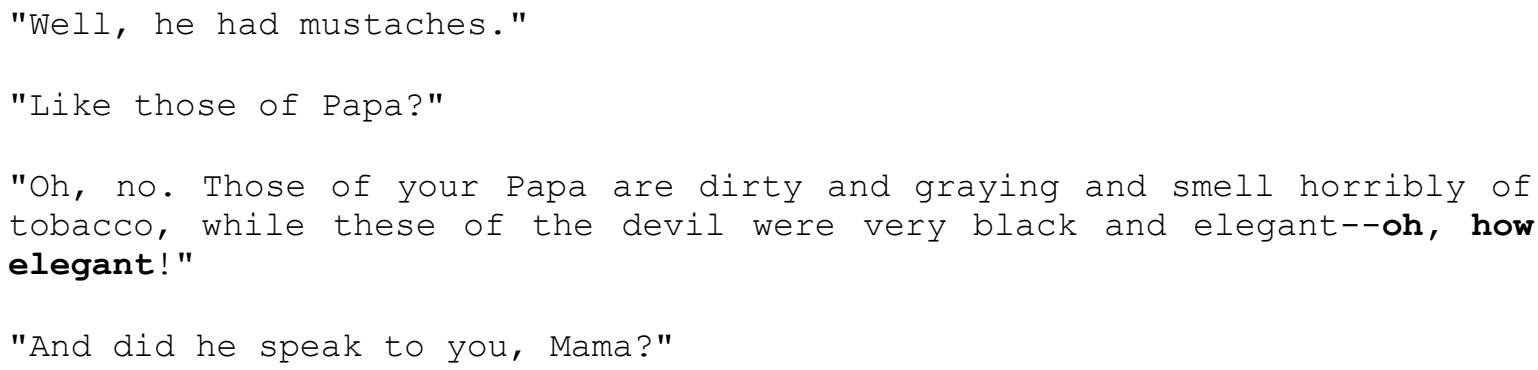

The excerpt above explicitly shows that Agueda used the word elegant in her utterance while discoursing with her daughter. The phrase "oh, how elegant!" does not show any specific information about the mustache she saw, but it shows her emotional reaction to what she saw. Her daughter asked her if the mustache she saw was the same with the mustache of Badoy, in which she answered no, then she describe the mustache as black and elegant, and 
she repeated the word elegant, which shows her feeling of amusement while remembering the mustache of the devil.

\section{Emphatic Stress}

According to Khoirot (2016), Emphatic Stress is a linguistic feature of women that is used as a boosting device used to strengthen the meaning of an utterance. It has similarities with intensifiers since both reflect the use of absolute superlative. Another meaning of emphatic stress is a question intonation on sentence, which is not a question. This is a central idea as women are powerless or weak. Women prefer to use emphatic stress to emphasize, compare, correct, or clarify things in the utterance, and to strengthen an assertion.

Out of the Ten Women's Linguistic Features by Robin Lakoff, Agueda uses Emphatic Stress the most as one of her linguistic features, consisting of twenty-two (22) utterances. Below are some of Agueda's utterances that contain Emphatic Stress.

\section{Excerpt 3:}

"Your mother told me to stay here all night, my grand lady!"

"And I will not lie down!" cried the rebellious Agueda, leaping to the floor. "Stay, old woman. Tell me what I have to do."

In the excerpt above, there are three emphatic stresses taken by Agueda; I will not lie down, Stay, old woman and Tell me what I have to do. These utterances are taken in Agueda's conversation with the old Anastasia when she was told to go to sleep. Agueda did not want to sleep, and she showed this by trying to show assertiveness in her utterances to Anastasia. The utterances above explicitly show emphatic stress because of the interjection mark shown emphasize to Agueda's utterance, and because of the authoritative language that Agueda used even though Anastasia is much older than her.

\section{Excerpt 4:}

"Go to the devil!"

"What a temper has my serrana!"

"I am not your serrana!"

"Whose, then? Someone I know? Someone I have offended grievously? Because you treat me, you treat all my friends like your mortal enemies."

Excerpt 4 is taken when the drunk Badoy insisted on dancing with Agueda in which she furiously refused. The excerpt clearly shows Agueda's assertiveness towards Badoy through the language that she used, which was uncommon for Filipino women to say during the 1800s. The statement also gives emphasis to the utterance because of the interjection mark. Also, the word not intensifies the adjective serrana (ideal woman), this adjective is expressed with the rising intonation, therefore making it an emphatic stress. The Emphatic stress used by Agueda has the same characteristic as intensifier, both use the word so, very, such, and quiet frequently but they have different intonations in expressing those words; however, Emphatic stress concerns more in stress and intonation than an intensifier. 


\section{Avoidance of Strong Swear Words}

Swearing is a kind of interjection that can express extreme intensity. In other words, avoidance of strong swear words are avoiding the use of a strong expletive expression. It has been widely considered as an expression of powerful emotion (Eckert, 2003 cited in Khoirot, 2016). Rafi (2014) averred that in avoidance of strong swearwords, women usually use softer forms such us Oh, Dear!orDarn!while the men use stronger ones such as Dammit! or Shit!. The research is able to find two (2) utterances that show Agueda's avoidance of strong swear words. One example of the utterances is shown in the excerpt below:

\section{Excerpt 5:}

"...We have no grace like the Parisiennes, we have no fire like the Sevillians, and we have no salt, no salt, no salt! Aie, how you weary me, how you bore me, you fastidious men!"

In the above utterance, Agueda expresses her feeling by saying “...Aie, how you weary me..." to express her emotion towards Badoy. Aie can be considered as a word used to avoid a stronger swear word despite Agueda's disgust towards Badoy. Swearing is widely considered as an expression of strong emotion, and is viewed as a potent language which is considered unsuitable for women.

The utterance of Agueda is an example that shows how women tend to use milder expletives than men. This is because, as children, women are encouraged to be demure, polite, and are not allowed to show their temper. Moreover, as cited in Nafilaturif'ah (2017), women are allowed to complain and fuss, but only men can rage their anger and disappointment. The stronger and forceful someone expresses his/her opinion, the more likely he/she will be taken seriously. Men are allowed to express stronger means than women because men have a stronger position in society.

\section{Intensifier}

The Intensifier is one of the women's linguistic features that functions as a way of backing out of committing oneself strongly to an opinion, to persuade their addressee to take them seriously, and to strengthen the meaning of their discourse (Lakoff, 2004). The kind of intensifiers which are commonly found in women's language includes must, too, so, just, very, quite, etc. Based on the research there are five (5) utterances of Agueda that use intensifiers. Below is an example of Agueda's utterance:

\section{Excerpt 6:}

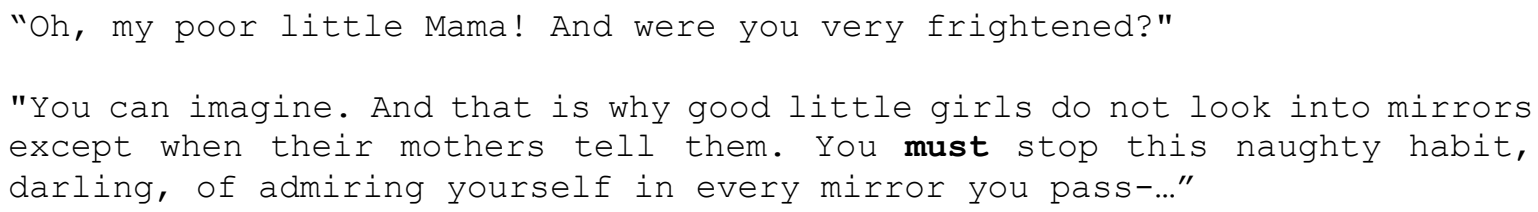

The excerpt above shows another conversation of Agueda with her daughter: here they are talking about the devil Agueda saw one evening while she was looking in the mirror. In Agueda's utterance she used the word must to emphasize the reminder she is giving her daughter. The intensive word is used by Agueda to persuade her daughter to take her reminder seriously. 
Moreover, intensifier is used more often by women than men, making it a characteristic of women's language. Men seem to have difficulty in constructing or adding intensifiers in their language when the sentence is unemotional. Intensifiers can be expressed by combining word classes like adverbs and adjectives.

\section{Stance Acts of Agueda}

In this part, the researchers will present the analyzed data of Agueda's utterances based on Du Bois' Theory of Stance. According to Du Bois (2007), Stance can be approached as a linguistically articulated form of social action whose meaning is to be constructed within the broader scope of language, interaction, and sociocultural value. Setting the problem in this way brings into play several aspects of language in interaction. Moreover, she also averred that stance, as a mean of public act, can be achieved dialogically by social actors through overt communicative means, of simultaneously evaluating objects, positioning subjects (self and other), and aligning with other subjects, with respect to any salient dimension of the sociocultural field.

There are three types of stance acts, namely evaluation, positioning (epistemic and affective), and alignment. The following figure illustrates the findings in terms of Agueda's stance takings.

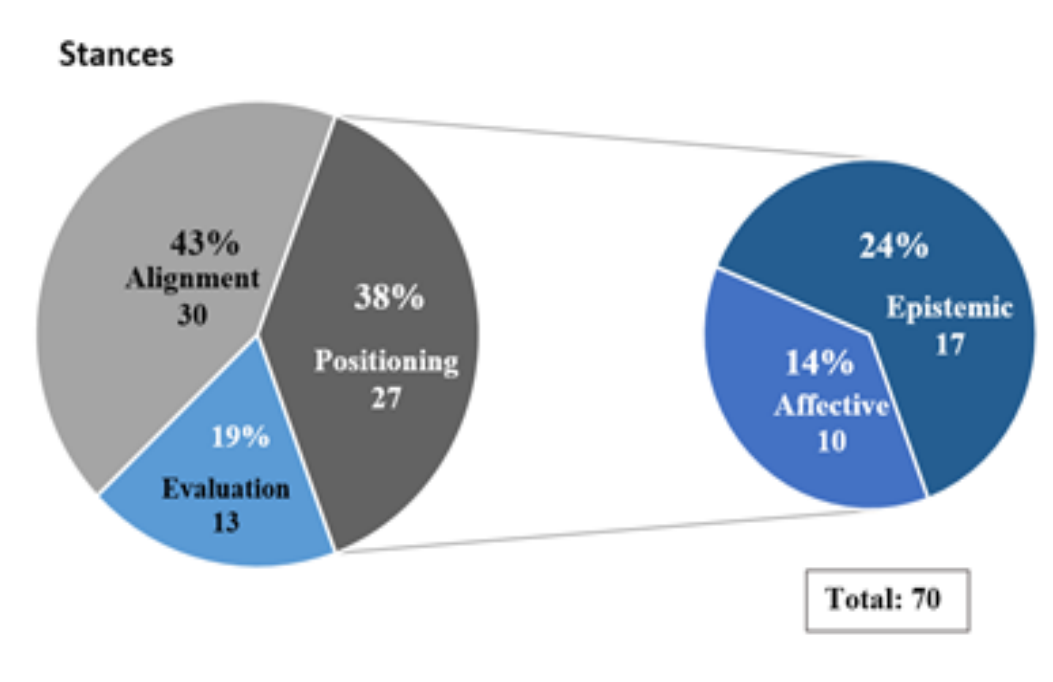

Figure 2 Agueda's Stancetakings

In Figure 2 it can be seen that alignment stance is the most frequently used stance by Agueda which constitutes 30 or $43 \%$ of the total stance. Meanwhile, the least frequently used stance is the Evaluation stance, which constitutes of 13 or $19 \%$ of the total stance taken by Agueda. Positioning stance, on the other hand, is in the middle frequency, which constitutes 27 or $38 \%$ of the total stance. The result is analyzed in order of evaluation, positioning (effective and epistemic), and alignment.

\section{Evaluation}

Evaluation is the process whereby a stance taker orients to an object of stance and characterizes it as having some specific quality or value (Du Bois, 2007). There is a total of 13 (19\%) utterances of Agueda that contains Evaluative Stance.

Here is an example of Agueda's Evaluative Stance: 


\section{Excerpt 7:}

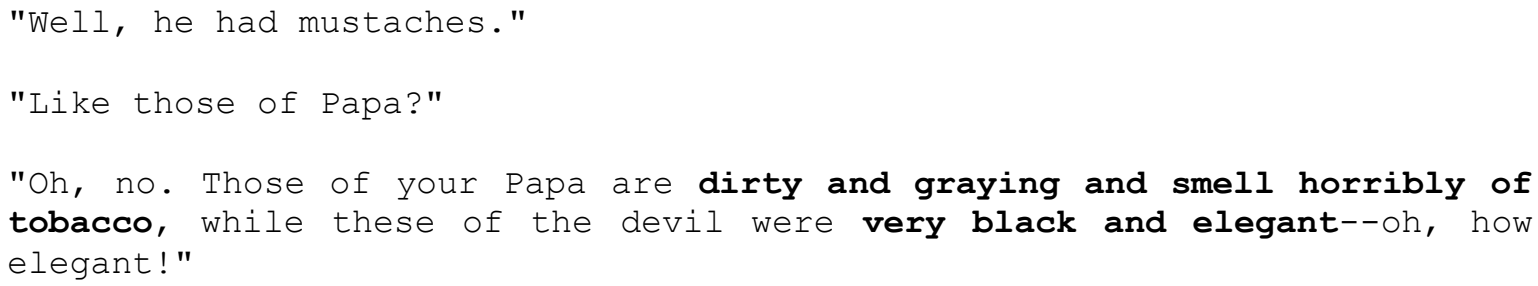

In excerpt 6, Agueda, while talking to her daughter, evaluated the physical attribute of the monster she saw on May day eve and compared it to her husband. The object of her stance is the mustache of his husband and those of the devil. Agueda evaluates her husband's mustache by asserting the stance predicate dirty and graying, and smell horribly of tobacco which implies a negative value to the object of the stance. On the other hand, she uses the evaluate stance very black and elegant to evaluate the devil's mustache, and compared to how she evaluates her husband's mustache; this implies a positive value on the object evaluated.

In sum, Agueda's evaluative stance covers people, things, and social phenomena. Her evaluations consist of positive and negative value, depending on her view towards the subject and the situation.

\section{Positioning}

According to Du Bois (2007), Positioning is the act of situating a social actor with respect to responsibility for stance and for invoking sociocultural value. Positioning as a stance is registered overtly through several discrete linguistic elements, including pronoun, verb, adjective, modals, and adverb. There are a total of 27 (38\%) positioning stances taken by Agueda. The data are further divided into two types, those utterances that contain Affective positioning and those that contain Epistemic Positioning.

\section{a. Affective Positioning}

Affective is the speaker's feeling about a proposition, an utterance, or a text (Irvine, 2009). There is a total of 10 or $14 \%$ positioning stances taken by Agueda. There are two kinds of lexical features in Agueda's affective stance predicate; these are verb and adjective. The affective stance predicate indexes specific aspects of the subject's feelings, positioning the speaker subjectively along some scale of affective value. Some lexical features found in Agueda's stances are categorized as follow:

1. Adjective: afraid, unsure

2. Verb: care, detest, bore, amuse

Below is an example of Agueda's affective stance controlled by adjectives and verbs.

\section{Excerpt 8:}

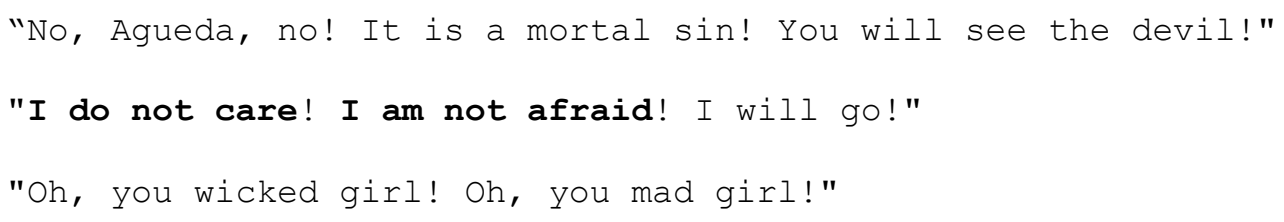


In the excerpt (7) above, there are two affective stances taken by Agueda. I do not care and I am not afraid. These stances indicate that person talking is the one taking the stance, as seen in the used of the personal pronoun $I$, which is then followed by the affective verb care and the affective predicate afraid. The first and second affective predicates express Agueda's determination to carry out the incantation that will lead her to see the man he will marry despite the warnings of her cousins that it is a mortal sin, and that she may see the devil while performing the incantation.

Consequently, Agueda communicates using affective stances to express her feeling and position herself along the affective scale. The use of affective predicate is varied; it can include, verb, noun, and adjective. Meanwhile, the object of her stance includes things, people, and situations.

\section{b. Epistemic Positioning}

The epistemic stance is the speaker's degree of commitment to a proposition (Irvine, 2009). It concerns with the truth-value of a proposition and the speaker's degree of commitment to it. There is a total of 17 or $24 \%$ epistemic positioning stances taken by Agueda. Below is an example of Agueda's utterance that contains an epistemic stance.

\section{Excerpt 9:}

"But where could I go, huh? Yes, I know! Down to the sala. It has that big mirror and no one is there now."

Based on Agueda's utterance above, she performs an epistemic stance by uttering Yes, I know and It has that big mirror and no one is there now. The object of the stance is the sala, and the stance predicate are yes, and I know. Agueda is also asking herself where she could find a big mirror where she can perform the incantation, the question she asked herself implies her request to know where she should go. The stance I know expresses Agueda's degree of certainty, and by uttering this epistemic stance, Agueda positions herself along the strong epistemic scale as knowledgeable.

Moreover, Agueda is showing firmness to do what she wants to do despite other people telling her not to. She expresses the degree of certainty and commitment to know who she will marry. Therefore, her speech shows she has a driven spirit compared to her cousins.

\section{Alignment}

Alignment can be defined provisionally as the act of calibrating the relationship between two stances, and by implication between two stancetakers (Du Bois, 2007). It implies agreement and disagreement with someone, which in conversation is usually the person being addressed. Alignment as a stance consists of two types, alignment, which consists of imitation, feedback, and agreement, and disalignment, which consist of changing the topic, disagreement, and refusal (Fatmawati, 2015). There is a total of 30 (43\%) utterances of Agueda that contains an alignment stance. Agueda's stances consist of feedback, agreement, changing topic, refusal, and disagreement. 


\section{Excerpt 10:}

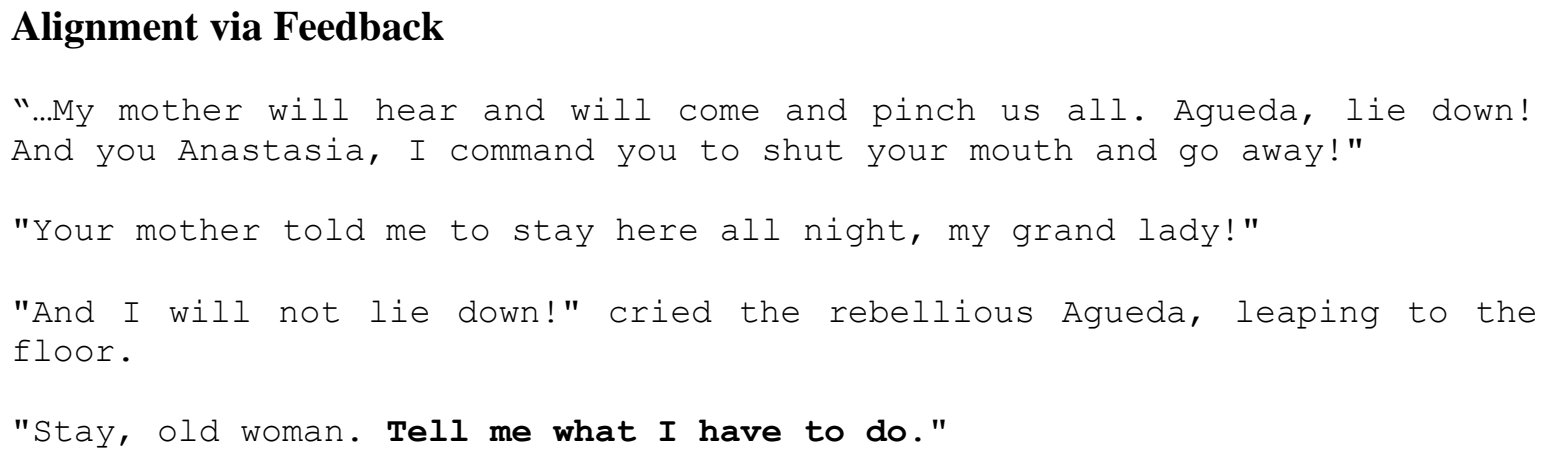

The utterance Tell me what I have to do, shows how she align herself with Anastasia, the old woman who is teaching them the incantation. The stance indicates that Agueda is willing to perform the incantation, and she wants Anastasia to tell her what she should do.

\section{Excerpt 11:}

\section{Alignment via Agreement}

"I saw the devil." she said bitterly. The child blanched.

"The devil, Mama? Oh... Oh..."

"Yes, my love. I opened my eyes and there in the mirror, smiling at me over my left shoulder, was the face of the devil."

In the conversation above, Agueda takes her stance in relation to her daughter's utterance. Agueda expresses her agreement when her daughter asked her if she really did see the devil in the mirror after performing the incantation. This stance indicates that Agueda takes a positive pole in the alignment stance.

\section{Excerpt 12:}

\section{Disalignment via Refusal}

"...My mother will hear and will come and pinch us all. Agueda, lie down! And you Anastasia, I command you to shut your mouth and go away!"...

"And I will not lie down!" cried the rebellious Agueda, leaping to the floor.

In the excerpt above, by uttering, I will not lie down. Agueda is expressing her refusal to follow her cousin when she told her to lie down or her mother might come and hear them. Her refusal indicates her disalignment with her cousin's utterance.

\section{Excerpt 13:}

\section{Disalignment via Disagreement}

"What a temper has my serrana!"

"I am not your serrana!" 
In Agueda's stance utterance, I am not your serrana, the adverb not explicitly assets her disagreement with Badoy's character when he addressed her as his serrana (ideal woman). Agueda, in her utterance, takes the negative pole in terms of alignment.

\section{Excerpt 14:}

\section{Disalignment via Changing Topic}

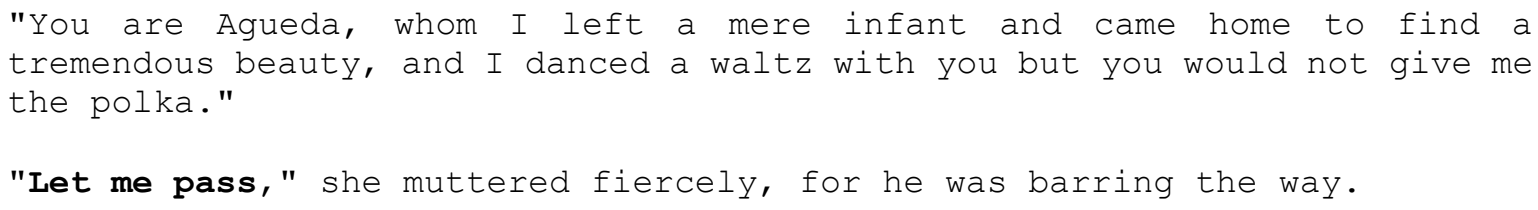

In the utterance of Agueda in the excerpt above, she preferred to change the topic by telling Badoy to let her a pass instead of directly giving him feedback related to what he is saying. Agueda takes the negative pole in her stance; she changed the topic for Badong to stop from bothering her and for insisting on dancing with her.

The findings show that Agueda's disalignment stances constitute 17 times, whereas her alignment stances constitute 13 times. This shows that Agueda does take the negative pole towards her interlocutor. Moreover, this can indicate Agueda's strong personality to express what she thinks, feels, or wants, whether it is contrary or not to her interlocutor.

Therefore, Agueda constructs her identity through stancetaking by evaluating the object or person, positioning herself along the affective or epistemic scale, and aligning or disaligning with her interlocutor. As a result, Agueda shows a personality that is very different from the personality set by society for Filipina women during her time.

\section{The Composite Identity of Agueda}

The findings reveal that Agueda's linguistic features and stance taking create her identity. The linguistic features indicate the various ways Agueda produces her utterances. Meanwhile, she takes the stances in order to evaluate, position, and align herself, among others.

Regarding Agueda's Linguistic Features, the researchers found that some of the women's linguistic features were not found in Agueda's utterances. Out of the 10 women's linguistic features, there are only 5 linguistic features found in Agueda, namely, lexical hedges or fillers, empty adjectives, avoidance of strong swear words, intensifier, and emphatic stress. Other linguistic features namely, tag question, rising intonation on declarative, super polite form, hypercorrect grammar, and precise color term were not found simply because Agueda does not need to talk using these features. Among the linguistic features found, with a total of 22 utterances, emphatic stress is found more often in her utterances. This implies that Agueda tends to commit herself strongly to her opinion. The emphatic stress in her sentences also indicates that Agueda tends to show her assertiveness in declaring her statements.

From the analysis, Agueda tends to add hedges in her utterances especially when talking to her daughter for her to make time to think about what she is going to say. It helps her to avoid making wrong sentences/utterances in front of her daughter. This is used by women to show positive politeness, indicating sensitivity to others' feelings. Moreover, it is used 
when discussing sensitive topics which may produce strong emotions in the speaker and their interlocutor.

Furthermore, there is only one utterance of Agueda that contains empty adjectives. This utterance shows the emotion she felt about the object, and not to describe the appearance of the subject.

Additionally, Emphatic Stress has the highest frequency in Agueda's linguistic feature. Based on the data, it can be implied that Agueda wanted to show the strength of her assertion through her language. Through this linguistic feature, Agueda was able to express herself more, and she is not afraid to say whatever she wanted to say. This clearly shows the personality of Agueda is very different from the women during her time; she is not afraid to express her opinion even if women's opinions were not taken seriously during her time.

Another linguistic feature, the avoidance of strong swear words, was also found in Agueda's utterance. However, only two utterances of Agueda contain this linguistic feature. These utterances, however, do not express extreme intensity, but a strong emotion of frustration.

Further, Intensifier was also found in Agueda's utterances, which implies Agueda's strong commitment to her opinion. This clearly shows how assertive and forceful Agueda really is to her opinion. Agueda uses this linguistic feature to persuade the person she is talking to, to believe and take her opinion seriously. She also uses this linguistic feature because women during her time are not listened to by other people especially by men, believing that women's opinion does not matter since men should always be the one to make a decision.

As a final point, based on the data analyzed, it can be implied that Agueda as a woman tends to break Lakoff's Theory of Women's Linguistic Features. It can also be deduced that based on her linguistic features, Agueda tends to depart from the standard set by society on how women should speak. The women in the Philippines are taught to speak with demeanor and grace, but it is a different case for Agueda. It only showed that Agueda has a strong personality, in expressing what she feels and what she wants to say, without conforming to the norms of how women should act.

Meanwhile, among the three kinds of stances, alignment stance is frequently used by Agueda, which consists of a total of 30 (43\%) utterances. It is then followed by positioning with a total of 27 (38\%), and lastly by evaluation with $13(19 \%)$ utterances. As Du Bois (2007, cited in Fatmawati 2015) noted, the relationship between stance and identity relies on the relation between the stancestaker's feelings about the object being talked about, and the speaker's personal feeling or understanding and another person's utterance. Agueda constructs her identity through stancetaking by evaluating an object, positioning himself along the affective or epistemic scale, and aligning or disaligning with his interlocutor.

The findings on Agueda's stances show that she evaluates people, things, and situations. Her evaluation consists of positive and negative values, depending on his view towards the subject of stance. Moreover, Agueda performs affective positioning stances to express her feelings and to position himself along the affective scale. Agueda uses verb and adjective as stance predicate. The object of her stance includes people, things, situations, and emotions.

To express his degree of commitment towards the object of stance, Agueda performs epistemic stances. The lexical features or the stance predicate in Agueda's epistemic stance consist of adverb, adjective, verb, conjunction, and modal. 
On the other hand, Agueda assorts herself towards his interlocutor by taking alignment and disalignment. Agueda takes alignment stances via Agreement and Feedback, while for disalignment, he takes the stances via Refusal, disagreement, and changing of the topic. Moreover, the utterances of Agueda shows that the way she evaluates objects, position herself in an utterance, and align herself with her interlocutor.

The data gathered both in the linguistic features and the stances taken by Agueda can clearly infer that Agueda is a strong-willed young woman, compared to other women of her time; she is young, bold and liberated, who wants to do whatever she wants. She is very assertive to do what she wanted to do without minding who the person she is talking to, and what the norms are in the society that she is living. Through her utterances, it can be deduced that Agueda was able to show the other personality women possess, that despite living in a patriarchal society, some women are not afraid to assert their opinion, and to do what they wanted to.

\section{CONCLUSION}

This paper purports to analyze the women's linguistic features found in Agueda's utterances and to create her identity through her stance taking. Previous studies have examined the identity of Agueda. However, none have looked deeper into analyzing her language use. This paper proves valid undertakings, particularly taking into account the implicit and explicit expression of Agueda in her language.

Based on the research, it can be concluded that language is an important factor in creating an identity of a person, and this identity can be formed through stances and linguistic features. Based on the women's linguistic feature and stances analyzed, the researchers were able to conclude that the language and identity of Agueda was greatly affected by the society, the culture, and the people that surrounded her. She was assertive and strong-willed who follows and do what she wanted to do and say, despite being a woman in a patriarchal society. However, same with other women, Agueda was also a woman who is curious and fascinated with the idea of love and marriage that lead her to seeing Badoy, the man she considered as a devil. However, the strong personality of Agueda is no match to the rules set by the society during her time. She was forced to marry Badoy, and her utterances also showed how resentful she has become after their marriage.

Nevertheless, despite her antipathy towards Badoy, her utterances still show how careful and sensible she was as she talked about Badoy with her daughter. Lastly, the identity of Agueda reflects the status of women living in a patriarchal society who wanted to be able to express and assert their opinion, which are sometimes being oversighted. Some women are not given the same rights and privileges given to men. Despite having the right, most women are still influenced to follow the traditions and rules in society.

\section{REFERENCES}

Ahmad (2014). Language and Gender Differences in Jordanian Spoken Arabic: A Sociolinguistics Perspective. Theory and Practice in Language Studies, 4(5) pp. 872882. 
Bamberg, M., De Fina, A. \&Schriffin, D. (2011). Language and Identity Construction. In. S.J.

Du Bois, J. (2007). The Stance Triangle in R. Englebertson (Ed.), Stancetaking in Discourse: Subjectivity, Evaluation, Interaction. Amsterdam/Philadelphia: John Benjamins Publishing Company.

Fatmawati (2015). Mikhail's Personal Identity Construction in Paulo Coelho's The Zahir. NOBEL: Journal of Literature and Language Teaching, 6(2), 97-120.

Holmes, Janet. (2008). Introduction to Sociolinguistics (3rd Ed).Pearson Longman: New York.

Irvine, J.T. (2009). How Mr. Taylor Lost His Footing: Stance in a Colonial Encounter. In A.M.

Jaffe (Ed.), Stance: Sociolinguistic Perspective, (pp. 53-71). Oxford: Oxford University Press.

Khoirot, A. et al. (2016). Women's Linguistic Features in Two Dramas. Nobel: Journal of Literature and Language Teaching, 7(1) 49-64.

Lakoff, R. (1975). Language and Woman's Place. Language in Society. Cambridge University Press, 2(1) 40-80.

Nafilaturif'ah. (2017). Katniss Everdeen's Linguistic Features and Personal Identity Construction in Suzanne Collins' The Hunger Games. Unpublished Undergraduate Thesis. English Department, Faculty of Arts and Humanities. The State Islamic University of SunanAmpel Surabaya.

Pan, Q. 2011. On the Features of Female Language in English. Theory and Practice in Language Studies, 1 (8): 1015-1018.

Wardhaugh, R. (1987). Languages in Competition: Dominance, Diversity, and Decline (The Language Library). Oxford: Blackwell Publisher: 978-0631157458.

Wildemuth B. \& Zhang Y. (2015). Qualitative Analysis of Content. Analysis 1 (2):1-12 (2005) 